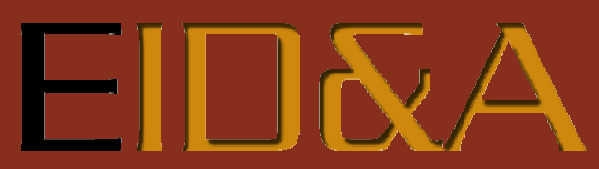

Revista Eletrônica de Estudos Integrados em Discurso e Argumentação

http://dx.doi.org/10.17648/eidea-15-1756

\title{
POR UM CONTÍNUO DAS FORMAS DE DISCURSO REPRESENTADO
}

\author{
Gustavo Ximenes Cunhai
}

Resumo: Neste trabalho, que se filia a uma perspectiva enunciativa dos estudos da linguagem, explora-se a hipótese de que as formas de discurso representado podem ser dispostas ao longo de um contínuo que estude essas formas por meio dos diversos graus de absorção da enunciação representada pela enunciação produzida. Para obter o contínuo mencionado, este trabalho se baseou no estudo de 53 sequências narrativas extraídas de oito reportagens veiculadas em revistas semanais de informação. No polo esquerdo do contínuo, o discurso direto explícito permite ao locutor delimitar a fronteira entre o discurso representado e o discurso produzido. Mais próximo desse polo, o discurso direto implícito corresponde a um segmento que traz uma fala de amplo conhecimento, mas sem identificação da instância responsável pela fala. Aproximando-se do polo direito, o discurso indireto implícito dilui mais a fronteira entre os discursos produzido e representado, permitindo apenas via contexto a identificação das vozes dos enunciadores. No polo direito, o discurso indireto explícito apaga todos os vestígios da enunciação representada, havendo apenas uma enunciação, a produzida.

Palavras-chave: Continuo. Formas de discurso representado. Dialogismo. Polifonia.

Abstract: This paper, which is based on an enunciative perspective of language studies, argues that the forms of represented discourse can be arranged in a continuum, in which these forms correspond to different degrees of absorption of the represented enunciation by the produced enunciation. To arrive at the mentioned continuum, this work was based on the study of 53 narrative sequences extracted from eight reports published in weekly informative magazines. In the left pole of the continuum, explicit direct discourse allows the speaker to delimit the boundary between the represented discourse and the produced discourse. Near this pole, implicit direct discourse brings a speech of ample knowledge, but without identification of the person responsible for it. Near the right pole, implicit indirect discourse dilutes the boundary between the produced and the represented discourses, allowing only through context the identification of the voices of the speakers. At the right pole, explicit indirect discourse erases all vestiges of the represented enunciation. In this form, there is only the produced enunciation.

Keywords: Continuum. Represented discourse. Dialogism. Polyphony.

\footnotetext{
'Este artigo apresenta parte dos resultados da pesquisa de doutorado relatada em Cunha (2013).

ii Professor Doutor da Universidade Federal de Minas Gerais (UFMG) e do Programa de PósGraduação em Estudos Linguísticos da UFMG, Brasil. E-mail: ximenescunha@yahoo.com.br.
} 
EID\&A - Revista Eletrônica de Estudos Integrados em Discurso e Argumentação, Ilhéus, n. 15, jan./jun.2018.

\section{Introdução}

Nos estudos da linguagem, diferentes obras, entre as quais se destacam as de Bakhtin/Volochínov (1986[1929]), Ducrot (1987) e Authier-Revuz (1990), provocaram, nas últimas décadas, um crescente interesse pela problemática do dialogismo e da polifonia. Subjaz a esse interesse a percepção de que uma abordagem estritamente linguística e, em especial, sintática não dá conta da natureza essencialmente enunciativa que caracteriza a representação do discurso alheio nas suas mais diversas manifestações linguísticas e textuais (discurso direto, indireto ou indireto livre, paráfrase, ironia, negação polêmica, ilha enunciativa, pressuposição etc) (MAINGUENEAU, 1993). Desse modo, mais do que uma simples questão de subordinação sintática ou seleção lexical, os fatos de polifonia dizem respeito a um processo por meio do qual uma dada instância enunciativa (locutor para Ducrot (1987)) representa em seu discurso o ponto de vista ou a voz de outra(s) instância(s) enunciativa(s) (enunciador(es) também para Ducrot (1987)) ${ }^{1}$.

Nesse enfoque enunciativo, os discursos representados ${ }^{2}$ podem ser formulados pelo locutor de diferentes formas, que correspondem a graus maiores ou menores de "absorção" da enunciação representada pela enunciação produzida. Com efeito, as diferentes formas de discurso representado podem ser dispostas em um contínuo, que vai desde uma apresentação direta e explícita da voz do outro até uma subordinação quase completa dessa voz àquela responsável pelo discurso produzido.

De modo mais ou menos explícito, a ideia de um contínuo das formas de discurso representado está presente na abordagem de diferentes autores. Fiorin (2010) explora essa ideia, valendo-se da terminologia tradicional (discurso direto, indireto e indireto livre), mas segundo um enfoque enunciativo. Com base em Roulet (1995), Perrin (1996) também propõe um contínuo das formas de discurso representado, na busca por mostrar ser

\footnotetext{
${ }^{1}$ Nas últimas décadas, as noções de dialogismo e polifonia têm fomentado debates e, desse modo, têm sido objeto de diferentes conceituações nos estudos da linguagem. Por isso, esses termos remetem a conceitos que, embora aproximados, guardam especificidades dependendo do autor em questão e da vertente teórica em que se insere (Análise do Discurso, Retórica, Linguística Textual, Pragmática etc). Como a retomada desse debate extrapolaria os limites deste estudo, remetemos o leitor interessado aos seguintes trabalhos: Maingueneau (1993), Brait (1997), Fiorin (2006) e Faraco (2009).

${ }^{2}$ Com base em Roulet (1999), utilizo o termo discurso representado para me referir ao que outras abordagens nomeiam discurso citado ou relatado. Com essa escolha terminológica, Roulet busca chamar a atenção para o fato de que nem todo discurso alheio é citado, ou seja, é a simulação da forma como dada fonte o teria, de fato, pronunciado ou escrito. Um segmento de discurso alheio pode ser, por exemplo, a antecipação do que o locutor imagina que o interlocutor dirá.
} 
EID\&A - Revista Eletrônica de Estudos Integrados em Discurso e Argumentação, llhéus, n. 15, jan./jun.2018.

gradual a distinção entre textos dialogais e monologais. Relacionando as problemáticas do apagamento enunciativo e do discurso relatado, Rabatel (2004) revela que a inscrição no discurso do locutor citado e do locutor citante é uma questão de graus e que um paradigma bastante variado de marcas linguísticas pode ser usado para expressar o grau maior ou menor de responsabilidade tanto de um quanto de outro sobre um dado ponto de vista.

Em perspectiva semelhante, este trabalho, que apresenta parte dos resultados da pesquisa relatada em Cunha (2013), tem como objetivo central explorar essa hipótese de que as formas de discurso representado podem ser dispostas ao longo de um contínuo que estude essas formas não apenas de um ponto de vista linguístico, mas também (e principalmente) enunciativo. Em outros termos, proponho um contínuo por meio do qual seja possível entender a manifestação linguística como reflexo de diferentes graus de absorção da enunciação representada pela enunciação produzida.

Quanto às formas do discurso representado consideradas neste trabalho, baseio-me em Maingueneau $(1993,1996,2008)$, Perrin $(1995,1996)$ e Dolabella (1999) para obter quatro formas que resultam da combinação de quatro parâmetros: direto vs indireto e explícito vs implícito, os quais permitem delimitar fatos de polifonia, apreendendo não somente elementos formais, mas ainda elementos enunciativos. Assim, o discurso representado pode ser formulado de modo direto ou indireto. É direto se houver marcas linguísticas e tipográficas (verbos de fala (dicendi), dois-pontos, travessão e/ou aspas) demarcando as duas enunciações, a produzida e a representada. É indireto se houver marcas sintáticas (subordinação, sintagmas preposicionais, orações conformativas) indicando a existência de apenas uma enunciação, a produzida. Tanto o discurso direto quanto o indireto podem ser explícitos ou implícitos, o que se refere à presença ou à ausência, respectivamente, de indicação da instância enunciativa responsável pelo discurso representado.

Com a combinação desses parâmetros, obtêm-se as quatro formas principais de discurso formulado: discurso direto explícito, discurso direto implícito, discurso indireto implícito e discurso indireto explícito. No esquema abaixo, evidencio a maneira como elas se posicionam ao longo do contínuo mencionado: 
EID\&A - Revista Eletrônica de Estudos Integrados em Discurso e Argumentação, Ilhéus, n. 15, jan./jun.2018.

\section{FIGURA 1 - Contínuo das formas de discurso representado}

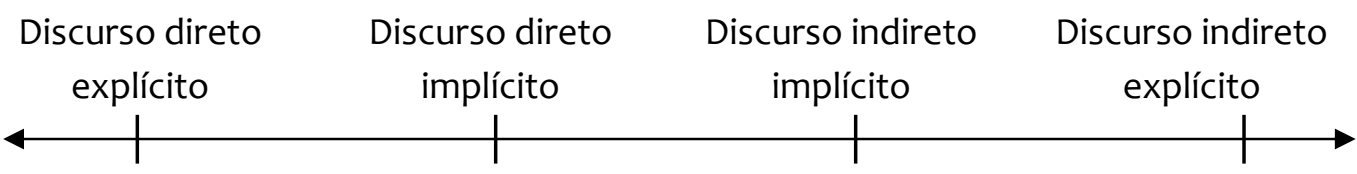

No polo esquerdo, o locutor "simula restituir as falas citadas" (MAINGUENEAU, 2008, p. 140), ao dissociar de forma clara as duas situações de enunciação, a do discurso produzido pelo locutor e a do discurso que representa. No polo direito, a absorção do discurso representado pelo discurso produzido é tal que se apagam todos os vestígios da enunciação representada, havendo apenas uma enunciação, a produzida. Nas posições intermediárias do contínuo, ocorrem misturas de elementos característicos das formas situadas nos polos. Como base empírica para a obtenção desse contínuo, utilizei um corpus de análise formado por 53 sequências narrativas extraídas de oito reportagens publicadas em edições de janeiro de 2010 de quatro revistas semanais (Carta Capital, Época, IstoÉ, Veja). Por isso, vale salientar que o contínuo proposto, embora possa, em trabalhos subsequentes, ser empregado na compreensão da maneira como ocorre a absorção do discurso representado pelo discurso produzido em outros tipos de discurso, é válido, sobretudo, para a compreensão do discurso jornalístico.

Ao longo deste trabalho, discutirei cada uma dessas quatro formas, utilizando excertos extraídos desse corpus de análise formado por sequências narrativas. Como veremos, essas formas de discurso representado se distribuem diferentemente pela estrutura das sequências narrativas. Assim, vale esclarecer que, em Cunha (2013), verifiquei que as sequências narrativas de reportagens correspondem, de modo mais ou menos aproximado, a um esquema (um tipo) narrativo composto por estes episódios: sumário, estágio inicial, complicação, avaliação, resolução, estágio final ${ }^{3}$. Demonstrando a pertinência do contínuo das formas de discurso representado por meio de

\footnotetext{
3 Em linhas gerais, o sumário oferece indicações sobre o conteúdo de que trata a sequência narrativa; o estágio inicial estabelece as coordenadas temporais e/ou espaciais dos acontecimentos tratados na sequência ou fornece informações que contextualizam esses acontecimentos; a complicação tematiza acontecimentos centrais que motivaram a própria escrita da reportagem; na avaliação, o jornalista ou um personagem avalia (reclama, prevê, critica, contesta etc) acontecimentos expressos em outros episódios; a resolução trata do resultado (previsto ou imprevisto) do acontecimento expresso geralmente na complicação; o estágio final indica os acontecimentos mais próximos do momento da publicação da reportagem (CUNHA, 2013). Para maiores esclarecimentos acerca dos procedimentos metodológicos adotados na elaboração desse tipo narrativo, bem como para a definição detalhada de cada episódio, cf. Cunha (2013, cap. 5).
} 
EID\&A - Revista Eletrônica de Estudos Integrados em Discurso e Argumentação, Ilhéus, n. 15, jan./jun.2018.

sequências narrativas extraídas de reportagens, este trabalho contribui para trazer esclarecimentos sobre a maneira como os jornalistas empregam essas mesmas formas como estratégias argumentativas capazes de produzir diversos efeitos de sentido.

\section{Discurso direto explícito}

Essa forma de discurso formulado se caracteriza por fazer parecer que o narrador reproduz exatamente as palavras ditas em outra situação de enunciação. Nesse sentido, ela "é um simulacro da enunciação construído por intermédio do discurso do narrador" (FIORIN, 2010, p. 72). Entre os autores que tratam dessa forma de discurso formulado, é consensual a ideia de que o uso do discurso direto explícito provoca um efeito de maior objetividade, exatamente por fazer parecer que é o outro que fala.

No discurso jornalístico, que se pretende desprovido de marcas de subjetividade, essa forma é particularmente relevante, porque por meio dela o jornalista pode

[...] apresentar autenticidade e autorizar o enunciado, aspecto essencial no funcionamento do discurso midiático; estabelecer distanciação face ao dito (o que contribui para a autorização do discurso, em particular no caso da citação de autoridades científicas); construir uma imagem de objectividade e seriedade, sempre associada a um jornalismo de qualidade (RAMOS, 2007. p. 53).

No corpus, $31(24,8 \%)$ de todas as 125 ocorrências de discurso representado identificadas são formuladas de forma direta e explícita. E, não por acaso, quase todas as ocorrências de discurso direto explícito estão na avaliação, episódio da sequência narrativa que tem como uma de suas características apresentar o ponto de vista de uma personagem acerca do acontecimento central abordado na sequência. De modo geral, no corpus, essa forma de discurso representado permite ao jornalista expressar o discurso de diversas fontes (testemunhas de catástrofes naturais, policiais, funcionários de instituições etc), fazendo parecer que entre elas e o leitor não há qualquer intermediário. A sequência abaixo exemplifica essa observação ${ }^{4}$ :

\footnotetext{
${ }^{4}$ Ao longo deste trabalho, adoto convenções que permitem visualizar a análise das formas de discurso representado nos segmentos extraídos das reportagens. Assim, o segmento correspondente a uma forma de discurso representado é delimitado por colchetes, segmento que é antecedido pela abreviação da instância enunciativa responsável pela informação nele expressa. Abaixo da sequência, entre parênteses, indico por extenso a denominação da instância. Quando a menção aos episódios da sequência narrativa (sumário, complicação, avaliação etc) se fizer
} 
EID\&A - Revista Eletrônica de Estudos Integrados em Discurso e Argumentação, Ilhéus, n. 15, jan./jun.2018.

(01) (Sumário) Enquanto a população se vira para ajustar a renda ao novo cenário, o governo não faz esforço para conter suas despesas. FI[(Estágio inicial) No ano passado, (Complicação) os gastos públicos chegaram a cerca de R\$় 145 bilhões, 17\% a mais que em 2008.] E[(Avaliação) "Não há mágica para melhorar a situação fiscal. Tem de haver redução de gastos e, eventualmente, aumento de arrecadação",] diz Zeina Latif, economistachefe do banco ING no Brasil. ("O bolívarforteficou fraco", Época, 15/01/2010)

$(\mathrm{FI}=$ fonte indefinida (dados do governo). $\mathrm{E}=$ economista. $)$

Ao representar de forma direta e explícita o discurso de uma economista sobre a economia da Venezuela, o jornalista, ao mesmo tempo, faz parecer que o leitor tem acesso direto à declaração da economista e reforça a autenticidade e a veracidade das informações expressas antes da declaração. Com isso, o jornalista faz da declaração da economista um argumento para defender a ideia que expressa no sumário: "Enquanto a população se vira para ajustar a renda ao novo cenário, o governo não faz esforço para conter suas despesas”.

No corpus, os segmentos de discurso direto explícito ocorrem principalmente entre aspas e seguidos de verbo dicendi (diz, conta, lamenta, avalia etc), como no exemplo anterior. Mas outras formas também ocorrem. Houve apenas esta ocorrência de discurso direto explícito antecedido por verbo dicendi e dois pontos:

(02) De uniforme azul, o cabisbaixo pedreiro Crispim Antonio de Souza, de 50 anos, lamenta: C["Hoje derrubo a casa dos outros. Amanhã pode ser a minha".] ("São Paulo na lama", Carta Capital, 20/01/2010)

$(C=$ Crispim. $)$

Em outras sequências, ocorre o que Maingueneau (2008) chama de "ilhas enunciativas". São fragmentos, palavras isoladas, sintagmas e atos completos entre aspas, cuja função é trazer para o interior do discurso produzido pelo narrador uma expressão atribuída a um personagem, como ocorre no trecho sublinhado desta sequência:

(03) Fl [No Rio de Janeiro, cenário da mais recente tragédia, só se gastou 1,17\% em ações preventivas.] O governador do Rio, Sérgio Cabral, culpou os G["40 anos de omissão dos políticos"] no Brasil. ("É possível evitar?", Época, 08/01/2010)

( $\mathrm{FI}=$ fonte indefinida (ministro da Integração Nacional, governador do Rio). $G$ = governador do Rio.)

necessária, eles serão indicados entre parênteses e em negrito. Algumas dessas convenções são utilizadas por Roulet (1999, ROULET; FILLIETTAZ; GROBET, 2001, cap. 10). 
EID\&A - Revista Eletrônica de Estudos Integrados em Discurso e Argumentação, Ilhéus, n. 15, jan./jun.2018.

Segundo Ramos (2007, p. 62), as ilhas enunciativas "estão ao serviço da criação de um forte 'efeito de real', pelo contraste com o co-texto imediato e pela ilusão de verossimilhança associada ao discurso directo". Nesse sentido, contribuem para fazer emergir no discurso produzido pelo jornalista 0 discurso de uma fonte ou, como ocorre no excerto (03), de uma figura política, criando, consequentemente, o efeito de que o leitor tem acesso direto ao dito.

Houve ainda um caso bastante interessante de discurso direto explícito sem aspas:

(04) M[São Luiz do Paraitinga não existe mais.] Os moradores da pequena cidade histórica no interior de São Paulo não se cansam de repetir esta frase desde a inundação que castigou a região, a partir da madrugada do dia 10 de janeiro. (“Eles não deveriam estar aqui", IstoÉ, 13/01/2010)

( $M=$ moradores. $)$

Nesse trecho, o enunciado "São Luiz do Paraitinga não existe mais" ocorre sem aspas e sem nenhuma outra indicação tipográfica de que se trata de um segmento de discurso representado. É somente a leitura do enunciado seguinte ("Os moradores da pequena cidade histórica no interior de São Paulo não se cansam de repetir esta frase") que permite compreender, de forma retroativa e por meio de uma expressão anafórica metadiscursiva (esta frase), que o primeiro enunciado representa o discurso produzido pelos moradores da cidade. Nesse caso, a ausência de aspas parece se dever ao fato de que a instância responsável pelo dito é uma classe de indivíduos ou um "enunciador genérico" (MAINGUENEAU, 2008) e não um indivíduo apenas. Com efeito, seria inverossímil dizer que todos os moradores, como em coro, vêm repetindo uma mesma declaração:

(05) Os moradores da pequena cidade histórica no interior de São Paulo não se cansam de repetir: "São Luiz do Paraitinga não existe mais".

Uma última observação sobre o discurso direto explícito diz respeito à natureza dos verbos dicendi. Maingueneau (1996) observa que a importância desses verbos está na influência que podem exercer sobre a interpretação do leitor. Afinal, como mostra Marcuschi (2007), o locutor, por meio desses verbos, pode valorizar, recriminar, reprovar um discurso representado e, consequentemente, a instância responsável por esse discurso. Maingueneau (1996), com base em Kerbrat-Orecchioni (1980), propõe distinguir esses 
EID\&A - Revista Eletrônica de Estudos Integrados em Discurso e Argumentação, Ilhéus, n. 15, jan./jun.2018.

verbos em duas classes. A primeira é composta pelos verbos com valor descritivo (repetir, dizer etc). A segunda se compõe dos verbos com valor apreciativo, que expressam um julgamento em relação ao discurso representado (reprovar, lamentar etc).

Nos segmentos de discurso direto explícito do corpus que são acompanhados de verbos dicendi, há mais verbos descritivos (afirmar, dizer, contar, avaliar, relatar, lembrar) do que verbos apreciativos (lamentar, sentenciar e reclamar). Essa desproporção parece se dever exatamente ao fato de que o emprego de verbos dicendi apreciativos revela o ponto de vista do locutor e não contribui para a produção de um discurso que, como o jornalístico, busca criar um efeito de objetividade. É o que ocorre no excerto (02), apresentado anteriormente e reproduzido a seguir:

(02) De uniforme azul, o cabisbaixo pedreiro Crispim Antonio de Souza, de 50 anos, lamenta: C["Hoje derrubo a casa dos outros. Amanhã pode ser a minha".] ("São Paulo na lama", Carta Capital, 20/01/2010)

$(C=$ Crispim. $)$

A interpretação de que a fala de Crispim constitui um lamento não é do próprio Crispim, mas do jornalista. Evidentemente, essa interpretação tem o potencial de influenciar a maneira como a fala da testemunha será compreendida pelo leitor, que, em função do verbo dicendi, poderá compreendê-la não como uma simples asserção, compreensão motivada pela estrutura declarativa das orações que compõem o depoimento, mas como uma reclamação da própria testemunha contra a situação de precariedade e de abandono em que se encontra. Dessa forma, o emprego de verbos dicendi apreciativos constitui uma estratégia argumentativa importante, já que esses verbos direcionam a leitura. Porém, essa mesma estratégia, se utilizada em demasia pelo jornalista, pode tornar o discurso excessivamente opinativo.

\section{Discurso direto implícito}

O discurso direto implícito ou discurso direto livre é "um discurso relatado que tem as propriedades linguísticas do discurso direto, mas sem nenhuma sinalização" (MAINGUENEAU, 2008, p. 148, grifo do autor). Conforme a caracterização proposta por Maingueneau, essa forma de discurso representado não apresenta qualquer indicação tradicional do discurso direto explícito (aspas, travessão, verbo dicendi e/ou dois-pontos), nem informação 
EID\&A - Revista Eletrônica de Estudos Integrados em Discurso e Argumentação, Ilhéus, n. 15, jan./jun.2018.

sobre a instância responsável pelo dito. A percepção de que se trata de discurso representado se baseia em informações linguísticas e referenciais.

Do ponto de vista linguístico, o segmento mantém os elementos dêiticos de pessoa, espaço e tempo da enunciação original, como ocorre no discurso direto explícito. Do ponto de vista referencial, o discurso representado é uma fala ou uma declaração de amplo conhecimento de uma comunidade de falantes. Assim, o locutor atribui ao interlocutor o conhecimento desse discurso e da instância que por ele se responsabiliza. Um exemplo de discurso direto implícito seria um artigo de opinião que trouxesse o segmento "Saio da vida para entrar na História" sem nenhuma indicação formal de que se trata de declaração atribuída a Getúlio Vargas. Nesse exemplo, o locutor pressupõe um interlocutor capaz de fazer essa atribuição.

No corpus, não houve nenhuma ocorrência de discurso direto implícito. Uma explicação para esse resultado parece residir na busca do jornalista por evitar o risco de o leitor não perceber que um dado trecho constitui um segmento de discurso representado e atribuir esse discurso ao próprio autor da reportagem. Outra explicação é a possibilidade de o leitor, mesmo notando o discurso representado, não conhecer a instância responsável por ele ou atribuir esse discurso a outra instância. A exigência de captação, que caracteriza o gênero reportagem, constitui uma restrição ao emprego de recursos linguísticos e discursivos que possam comprometer a legibilidade da reportagem (CHARAUDEAU, 2006). Dessa forma, a restrição imposta por essa exigência parece ser a responsável por não haver, nas sequências narrativas do corpus, ocorrências de discurso direto implícito.

\section{Discurso indireto implícito}

Essa forma de discurso representado, tradicionalmente denominada discurso indireto livre, se caracteriza pela mistura de duas vozes, a do narrador e a de personagens. Em um segmento de discurso indireto implícito, não é possível determinar com precisão quais palavras atribuir ao narrador e quais atribuir aos personagens. Isso porque, ao contrário das formas explícitas de discurso formulado, o discurso indireto implícito não possui marcas sintáticas e lexicais próprias e marcas típicas de atribuição enunciativa. É apenas o contexto que permite perceber uma discordância entre a voz do narrador e a voz de uma personagem e, consequentemente, a mistura de elementos de duas enunciações (MAINGUENEAU, 1993, 1996). Em outras palavras, no 
EID\&A - Revista Eletrônica de Estudos Integrados em Discurso e Argumentação, Ilhéus, n. 15, jan./jun.2018.

discurso indireto implícito, é possível inferir que o que foi dito o foi por outro, mas não há marcas tradicionais (verbos de fala, sintagmas preposicionais, como Segundo $X$ ) que explicitem a ocorrência da enunciação representada.

Ao tratar dessa forma de discurso representado, Fiorin (2010, p. 81) observa:

Se há dois atos enunciativos, há duas vozes: a do narrador e a de uma personagem. Só que a voz da personagem, ao contrário do que ocorre no discurso direto, não enuncia em primeira pessoa. Diferentemente do que acontece no discurso indireto, não há subordinação a um verbum dicendi e há exclamações, interrogações e torneios expressivos.

Porque combina características das formas explícitas, o discurso indireto implícito constitui uma forma híbrida, assim como o discurso direto implícito, apresentado anteriormente. Como constituem formas híbridas, os segmentos de discurso indireto implícito podem estar mais próximos do discurso direto explícito ou do discurso indireto explícito (FIORIN, 2010). No primeiro caso, os segmentos, à maneira do discurso direto explícito, apresentam marcas da enunciação representada (interrogações, exclamações, seleção lexical característica, repetições etc). No segundo caso, os segmentos, assim como no discurso indireto explícito, apresentam muito poucas marcas da subjetividade da personagem cujo ponto de vista se representa.

No corpus, essa foi a forma de discurso representado mais frequente. De todas as 125 ocorrências de discurso representado, 47 (37,6\%) são formuladas de modo indireto e implícito. A maior parte dessas ocorrências corresponde a segmentos em que é possível perceber/inferir a voz de uma fonte, a qual, no entanto, não é definida nas sequências em que os segmentos ocorrem, nem no cotexto. Vejamos um exemplo:

(06) Na Enseada do Bananal, na Ilha Grande, morreram 31 pessoas soterradas. Elas estavam na pousada Sankay e em cinco outras residências engolidas por uma avalanche na madrugada do dia $1^{\circ}$. FI[A pousada tinha licença de funcionamento da prefeitura, mas não a licença ambiental do estado. Mesmo se tivesse, o risco de deslizamento da encosta não teria sido analisado. As casas atingidas no Morro da Carioca, no centro de Angra, onde morreram 21 pessoas, tampouco tinham licença. Antes da tragédia, porém, a prefeitura dispunha de um programa para levar saneamento e iluminação pública para aquela área,] como se não houvesse um grave problema de segurança. ("Trágico, absurdo, previsível”, Veja, 13/01/2010)

( $\mathrm{FI}$ = fonte indefinida (funcionários da prefeitura, moradores da região, etc).) 
EID\&A - Revista Eletrônica de Estudos Integrados em Discurso e Argumentação, Ilhéus, n. 15, jan./jun.2018.

Como esclarece Charaudeau (2006, p. 147), “a instância midiática não pode, evidentemente, inventar as notícias". É por essa razão que no jornalismo, ao contrário do que ocorre na literatura, os acontecimentos narrados não podem ser fictícios. Essa impossibilidade tem impacto sobre a construção do narrador, que em um gênero como a reportagem não poderá ser onisciente, simulando saber tudo a respeito das personagens e dos acontecimentos da narrativa.

É essa impossibilidade que permite identificar na sequência acima a presença de uma outra voz (ou de um enunciador, nos termos de Ducrot (1987)) e não apenas a do locutor/jornalista. No trecho sublinhado ("A pousada tinha licença de funcionamento da prefeitura [...] um programa para levar saneamento e iluminação pública para aquela área”), o locutor traz informações a respeito da forma como a prefeitura de Angra dos Reis realiza a concessão de licenças para a ocupação de áreas de risco. Como no jornalismo os acontecimentos não podem ser fictícios, não podendo o locutor inventar informações sobre licenças ambientais de governos e prefeituras, infere-se que essas informações foram obtidas pelo jornalista junto a uma fonte, cuja identidade não é revelada. Em outros termos, nesse trecho, os acontecimentos parecem passar pelo "prisma perceptivo" (RABATEL, 2007, p. 351) de um personagem ou de um conjunto de personagens. Assim, o jornalista representa o discurso de um terceiro, mas o representa de modo indireto, porque não emprega marcas tipográficas (aspas e itálico) que indiquem haver outra enunciação, e de modo implícito, porque não identifica a instância enunciativa responsável pelas informações.

Essa forma de discurso indireto implícito está mais próxima do discurso indireto explícito do que do discurso direto explícito. Para transformar o segmento sublinhado em discurso indireto explícito, é suficiente anteceder esse segmento por Segundo um funcionário da prefeitura ou por Um funcionário da prefeitura informou que.

Conforme Charaudeau (2006), não identificar uma fonte, como ocorre em muitos segmentos de discurso indireto implícito do corpus, pode ter como consequência criar um efeito de evidência, por meio do qual o jornalista faz parecer que os acontecimentos narrados se produziram de fato e não foram "filtrados" pelo ponto de vista de uma fonte. 
EID\&A - Revista Eletrônica de Estudos Integrados em Discurso e Argumentação, llhéus, n. 15, jan./jun.2018.

Além dessa finalidade geral, o discurso indireto implícito parece ter como papel resumir ou combinar em apenas um segmento informações colhidas com diferentes fontes, como neste exemplo:

(07) FI [Famosa pelo patrimônio histórico e arquitetônico, São Luiz do Paraitinga ganhou ainda mais importância no cenário cultural por promover, a partir dos anos 1980, eventos musicais como a Semana da Canção e o Festival de Marchinhas. Seu Carnaval também atraía milhares de turistas. $O$ povo se aglomerava para brincar em torno de construções coloniais erguidas com técnicas antigas, como a taipa de pilão, mantidas com zelo pelo poder público.] ("Eles não deveriam estar aqui", IstoÉ, 13/01/2010)

(FI = fonte indefinida (moradores, prefeita, jornalista, secretário de Cultura etc).)

Esse trecho, que constitui o início de uma sequência narrativa sobre a destruição da cidade de São Luiz do Paraitinga por uma enchente, parece ter sido construído com informações que dificilmente foram coletadas pelo jornalista junto a uma fonte apenas. Ao contrário, ouvimos nesse segmento as vozes de funcionários da prefeitura, de moradores da cidade, do secretário de cultura e de outros jornalistas, instâncias enunciativas responsáveis por outros segmentos de discurso representado nessa mesma sequência. Assim, enquanto a informação sobre a forma como o povo brincava o carnaval pode ser atribuída a moradores, a informação sobre os eventos musicais ou sobre construções coloniais parece ser de responsabilidade do secretário de cultura. Da mesma forma, a informação de que essas construções eram "mantidas com zelo pelo poder público" parece poder ser atribuída à própria prefeitura ou a algum funcionário da prefeitura.

Em outros segmentos, o narrador utiliza o discurso indireto implícito aparentemente como recurso para proteger a fonte da informação.

(08) Na quarta-feira 13, o presidente Lula convocou os ministros da Defesa, Nelson Jobim, e da Secretaria Especial dos Direitos Humanos, Paulo Vannuchi. FI[A reunião tinha como objetivo acalmar os ânimos em torno de um decreto assinado pelo próprio Lula em dezembro, criando $03^{\circ}$ Programa Nacional de Direitos Humanos. Por intervenção direta do presidente, o ponto mais polêmico foi, então, modificado: a chamada Comissão da Verdade, que investigaria crimes de tortura durante os anos de chumbo, teve suas atribuições revistas. $O$ trecho sobre delitos de agentes da repressão política foi suprimido e um grupo de trabalho vai discutir como fazer a comissão funcionar sem arranhar a Lei de Anistia.] L["Esse negócio de punir os crimes da repressão política é um assunto para a Justiça, não é para o Executivo",] disse Lula. ("O passado ainda presente", IstoÉ, 20/01/2010)

$(\mathrm{L}=$ Lula. $\mathrm{FI}$ = fonte indefinida (assessor, outro jornalista, funcionário do governo, etc).) 
EID\&A - Revista Eletrônica de Estudos Integrados em Discurso e Argumentação, llhéus, n. 15, jan./jun.2018.

Nessa sequência, o jornalista faz parecer que ele esteve presente na reunião entre o então presidente Luiz Inácio Lula da Silva e ministros e acompanhou todas as decisões tomadas no encontro. Como é muito pouco provável que essa reunião tenha sido aberta à cobertura da imprensa, inferese que as informações expressas no trecho sublinhado ("A reunião tinha como objetivo acalmar os ânimos [...] e um grupo de trabalho vai discutir como fazer a comissão funcionar sem arranhar a Lei de Anistia.") foram passadas ao jornalista por uma fonte, a qual, por talvez ser confidencial, não pode ser revelada.

Como observa Charaudeau (2006), não revelar a fonte de um segmento de discurso representado pode ser prejudicial, porque, se permite criar um efeito de evidência, pode afetar a credibilidade do locutor/jornalista. Afinal, o leitor pode duvidar da veracidade das informações veiculadas nos segmentos de discurso indireto implícito e/ou da idoneidade da sua fonte, da qual não se conhecem a identidade e as intenções.

No conjunto dos segmentos de discurso indireto implícito, também há alguns cuja instância enunciativa é identificável no cotexto.

(09) Crispim mora com a família em uma casa de quatro cômodos no Jardim Pantanal, próximo de onde cumpria a amarga tarefa de demolição. C[№ dia da cheia, seus móveis ficaram meio metro submersos. Somente após duas semanas, a água saiu da residência.] ("São Paulo na lama", Carta Capital, 20/01/2010)

$$
(\mathrm{C}=\text { Crispim. })
$$

No trecho sublinhado, percebe-se que o narrador representa o discurso produzido por Crispim em outra situação de enunciação, o que se comprova pela possibilidade de anteceder o segmento por Crispim contou que. O mesmo fenômeno ocorre em:

(10) Foi só no começo da tarde do dia 2, quando as águas finalmente começaram a baixar, que os 10000 moradores de São Luiz do Paraitinga puderam ver toda a extensão da tragédia. $\mathbf{M}$ [O centro histórico, na parte mais baixa da cidade, parecia ter sido alvo de um bombardeio.] ("Trágico, absurdo, previsível", Veja, 13/01/2010)

( $M=$ moradores. $)$

No enunciado "O centro histórico, na parte mais baixa da cidade, parecia ter sido alvo de um bombardeio", o locutor representa o discurso dos moradores, porque é de acordo com o ponto de vista desses personagens que 
EID\&A - Revista Eletrônica de Estudos Integrados em Discurso e Argumentação, llhéus, n. 15, jan./jun.2018.

o centro histórico parecia ter sido alvo de um bombardeio. Com esse segmento de discurso indireto implícito, o jornalista parece ter como fim aproximar o leitor e os personagens, fazendo com que aquele veja o que estes viram. Com esse recurso, aumenta-se a tensão ou a dramaticidade da narrativa sobre uma catástrofe natural, o que contribui para atender à exigência de captação do gênero reportagem.

Quanto à distribuição do discurso indireto implícito pelos episódios do tipo narrativo da reportagem, é interessante notar que essa forma de discurso representado é a mais frequente nos episódios estágio inicial, complicação, resolução e estágio final ${ }^{5}$. Como exposto em Cunha (2013), são justamente esses os episódios que têm como matéria-prima acontecimentos e não comentários, resumos ou opiniões acerca dos acontecimentos.

Esse resultado é bastante relevante, porque evidencia uma tendência das revistas de informação de construir as narrativas de reportagens com informações cujas fontes são implícitas. Como vimos, algumas dessas fontes são identificáveis no cotexto, mas a maioria não pode ser definida por nenhuma indicação dada pelo narrador, o que, contrariando a exigência de credibilidade do gênero reportagem (CHARAUDEAU, 2006), pode colocar sob suspeita a veracidade e a autenticidade das informações veiculadas. E essa suspeita pode, em última análise, comprometer a confiança do leitor na capacidade de uma dada revista de informação de produzir um jornalismo considerado de referência.

\section{Discurso indireto explícito}

No discurso indireto explícito, "há apenas uma situação de enunciação; as pessoas e os dêiticos espaço-temporais do discurso citado são identificados, com efeito, em relação à situação de enunciação do discurso citante" (MAINGUENEAU, 2008, p. 150). Isso ocorre porque no discurso indireto explícito o discurso representado perde sua autonomia. Por isso, são eliminados todos os elementos que, no discurso direto explícito, seriam usados para expressar a subjetividade de um personagem (interrogações,

\footnotetext{
${ }^{5}$ Conforme a análise quantitativa apresentada em Cunha (2013) e elaborada com base no corpus formado pelas 53 sequências narrativas, as ocorrências de discurso indireto implícito apresentaram as seguintes porcentagens nos episódios mencionados: estágio inicial $=26(83,88 \%)$ em um total de 31 formas de discurso representado; complicação $=30(60 \%)$ em um total de 50 formas de discurso representado; resolução $=20(66,66 \%)$ em um total de 30 formas de discurso representado; estágio final $=4(80 \%)$ em um total de 5 formas de discurso representado.
} 
EID\&A - Revista Eletrônica de Estudos Integrados em Discurso e Argumentação, llhéus, n. 15, jan./jun.2018.

exclamações, interjeições etc). Assim, no discurso indireto explícito, "só existe a subjetividade do narrador" (FIORIN, 2010, p. 75). Nessa forma de discurso formulado, ocorre uma absorção completa do discurso representado pelo discurso produzido, o que justifica a colocação dessa forma de discurso em uma dos extremos do contínuo das formas de discurso formulado (Figura 1).

Como, ao contrário do discurso indireto implícito, a forma explícita não traz nenhum vestígio das palavras e do modo de dizer atribuíveis aos personagens, essa forma de discurso formulado focaliza apenas o conteúdo. Assim, ao representar um discurso de maneira indireta e explícita, a preocupação do narrador está em apresentar o que supostamente foi dito por um personagem e não a forma como ele disse.

No corpus, 24 (19,20\%) das 125 ocorrências de discurso representado são feitas de forma indireta e explícita. A maior parte delas ocorre na avaliação. Nesse episódio, 12 segmentos de discurso representado são formulados dessa maneira. Depois da avaliação, a complicação é o episódio que apresentou a maior quantidade de segmentos de discurso indireto explícito. Nesse episódio, 10 segmentos de discursos representados são indiretos e explícitos.

Esses resultados são interessantes, porque revelam as duas funções básicas que o discurso indireto explícito assume nas sequências narrativas de reportagens. Primeiramente, o narrador representa o discurso do outro para apresentar, na complicação, o acontecimento central da narrativa. Em seguida, ele representa o discurso do outro, para apresentar esse outro comentando, na avaliação, esse mesmo acontecimento. Nos dois casos, o locutor/jornalista se apresenta como alguém que tem por função deixar os outros falarem, apresentar pontos de vista diferentes do seu, promover um confronto de pontos de vista, o que contribui para a construção de um efeito de objetividade e de imparcialidade. A sequência abaixo ilustra essas duas funções:

(11) (Estágio inicial) Na semana passada, depois de sobrevoar de helicóptero o trecho do litoral fluminense mais castigado pelas chuvas, (Complicação) o ministro da Integração Nacional, Geddel Vieira Lima, anunciou que Mi[o governo federal vai liberar $\mathrm{R} \$ 80$ milhões para recuperar a cidade de Angra dos Reis e outros R\$ 50 milhões para a Baixada Fluminense.] (Avaliação) $O$ ministro admitiu que, Mi[em 2009, o governo gastou apenas $21 \%$ da verba de $\mathrm{R} \$ 650$ milhões destinada à assistência contra acidentes naturais, especialmente chuvas. A maior parte do orçamento serviu para reconstruir estradas e casas em Santa Catarina, cujo Vale do Itajaí foi arrasado pelas chuvas no fim de 2008.] (“Épossível evitar?”, Época, 08/01/2010)

$(M i=$ ministro. $)$ 
EID\&A - Revista Eletrônica de Estudos Integrados em Discurso e Argumentação, Ilhéus, n. 15, jan./jun.2018.

$\mathrm{Na}$ complicação, o jornalista apresenta um ministro anunciando a liberação de verbas para a reconstrução de áreas castigadas por chuvas. $\mathrm{Na}$ avaliação, o jornalista apresenta o mesmo ministro admitindo que, no ano anterior em relação à data do anúncio, o governo federal gastou menos do que o esperado com assistência contra acidentes naturais. Como se percebe, com essa forma de discurso representado, o jornalista pode se colocar como testemunha dos discursos que representa, ainda que, com essa forma de discurso e diferentemente do que ocorre no discurso direto explícito, a voz dos enunciadores perca sua autonomia e seja apresentada de forma indireta, ou seja, como uma recriação (paráfrase) do próprio jornalista. Com essa forma de discurso, o efeito de veracidade que se pode obter com o discurso direto explícito (são os personagens que falam) é atenuado em prol do efeito de que é o jornalista quem tem o controle sobre as perspectivas ou pontos de vista encenados em seu discurso (sou eu, jornalista, que digo o que as personagens falaram).

No corpus, a maior parte das ocorrências de discurso indireto explícito apresenta a forma tradicional, em que uma oração subordinada objetiva direta correspondente ao segmento de discurso representado complementa um verbo dicendi. É essa a forma que assumem os segmentos de discurso representado no exemplo anterior (anunciou que $X$; admitiu que $X$ ). Ao lado dessa forma canônica, o corpus apresentou outras configurações de discurso indireto explícito.

Em alguns casos, são orações adverbiais conformativas que indicam a existência de discurso representado.

(12) O cenário devastador na pequena São Luís do Paraitinga, cidade paulista de 20 mil habitantes encravada entre montanhas no Vale do Paraíba, os desmoronamentos em Angra dos Reis e Ilha Grande, no litoral fluminense, ou a queda da ponte sobre o rio Jacuí, no interior do Rio Grande do Sul, sugerem que Esp[uma parcela considerável da responsabilidade pelas catástrofes ocorridas recai sobre a ação humana,] como têm alertado alguns especialistas. ("A culpa não é só da natureza", Carta Capital, $13 / 01 / 2010)$

$($ Esp $=$ especialistas. $)$

Esse exemplo é particularmente interessante, porque mostra que a indicação de que uma oração subordinada é um segmento de discurso representado pode estar em outro termo do período (a oração adverbial 
EID\&A - Revista Eletrônica de Estudos Integrados em Discurso e Argumentação, Ilhéus, n. 15, jan./jun.2018.

conformativa) e não no verbo da oração principal (sugerem), que, nesse exemplo, não é um verbo dicendi.

Em outros casos, o termo do período que sinaliza a ocorrência de discurso representado, explicitando a fonte enunciativa, é um sintagma preposicional:

(13) Segundo Firmino, F[o decreto ajuda a diminuir a degradação, pois permite construções em 10\% de algumas áreas degradadas apenas com a condição de que o proprietário recupere os outros 90\% do terreno.] (“É possível evitar?", Época, 08/01/2010)

( $F=$ Firmino, presidente do Inea.)

(14) No caso do Rio Grande do Sul, [...] Eng[faltou ao poder público verificar as estruturas da ponte sobre o rio Jacuí, de 314 metros e com mais de 40 anos de vida útil no momento da queda,] conforme alegação de engenheiros civis nos dias seguintes ao acidente. ("A culpa não é só da natureza", Carta Capital, 13/01/2010)

(Eng = engenheiros.)

Há ainda casos em que o complemento do verbo dicendi não é um sintagma verbal, mas um sintagma nominal:

(15) [Andreu] Foi espancado e não viveu para contar A[a história]. ("O passado ainda presente", IstoÉ, 20/01/2010)

$(A=$ Andreu. $)$

(16) Quando Tom Jobim e Vinicius de Moraes compuseram T+V[Garota de Ipanema], em 1962, o Rio de Janeiro tinha metade do número de habitantes de hoje. ("Sol, mar e organização", Veja, 06/01/2010)

( $T+V=$ Tom Jobim e Vinícius de Moraes.)

Assim como no discurso direto explícito, os verbos dicendi utilizados para introduzir o discurso representado têm papel importante no discurso indireto explícito. Como vimos, esses verbos constituem recursos que podem influenciar a interpretação do leitor e dar pistas que revelem a opinião do locutor acerca do discurso do outro. É o que ocorre no exemplo (11), analisado anteriormente. Ao informar que "O ministro admitiu que, em 2009, o governo gastou apenas $21 \%$ da verba de $\mathrm{R} \$ 650$ milhões destinada à assistência contra acidentes naturais, especialmente chuvas", o jornalista, porque emprega $\mathrm{o}$ verbo admitir, atribui ao ministro uma falta, bem como a consciência dessa falta. 
EID\&A - Revista Eletrônica de Estudos Integrados em Discurso e Argumentação, Ilhéus, n. 15, jan./jun.2018.

Retomando a distinção proposta por Maingueneau (1996) entre verbos descritivos e apreciativos, verifiquei que, assim como no discurso direto explícito, os segmentos de discurso indireto explícito com verbo dicendi apresentam mais verbos descritivos do que apreciativos. Os descritivos encontrados foram: lembrar, reiterar, revelar, destacar, anunciar, dizer, explicar, afirmar, contar e compor. Os apreciativos foram: admitir, denunciar, garantir e discutir. Houve ainda uma ocorrência do verbo escancarar, que, embora não seja tipicamente um verbo dicendi e apreciativo, foi empregado com essa função no trecho abaixo:

(17) Poucas horas depois, as redes de tevê escancaravam para todo o Brasil que $\mathbf{R}$ [o absurdo da tortura não foi uma exclusividade da ditadura e que suas vítimas não se resumem à elite intelectual e política que hoje está no poder.] (“O passado ainda presente", IstoÉ, 20/01/2010)

( $R=$ redes de tevê.)

Aqui também a desproporção entre verbos descritivos e apreciativos se explica pela busca do locutor/jornalista de construir um discurso que pareça objetivo e livre da sua subjetividade.

\section{Considerações finais}

Com este trabalho, procurei defender a hipótese, já explorada por outros autores (FIORIN, 2010, ROULET, 1995, PERRIN, 1999, RABATEL, 2004), de que as formas de discurso representado podem ser dispostas ao longo de um contínuo que reflete o grau maior ou menor de absorção do discurso representado pelo discurso produzido. Para elaborar o contínuo apresentado na Figura 1, utilizei quatro parâmetros (direto vs indireto e explícito vs implícito) que, combinados, dão origem a quatro formas: discurso direto explícito, discurso direto implícito, discurso indireto implícito e discurso indireto explícito. Porque correspondem a diferentes graus de absorção do discurso representado pelo discurso produzido, essas formas permitem ao locutor alcançar diferentes efeitos de sentido.

No polo esquerdo do contínuo, o discurso direto explícito permite ao locutor promover o efeito de objetividade, já que, demarcando claramente a fronteira entre o discurso produzido e o representado, simula reproduzir com exatidão o discurso elaborado em outra situação. 
EID\&A - Revista Eletrônica de Estudos Integrados em Discurso e Argumentação, llhéus, n. 15, jan./jun.2018.

Manifestando um grau menor de absorção do discurso representado pelo produzido, o discurso direto implícito corresponde a um segmento que traz uma fala de amplo conhecimento de uma dada comunidade. Embora não apresente qualquer indicação da instância responsável pelo dito, essa forma de discurso mantém a fronteira entre a enunciação representada e a produzida, uma vez que carrega os elementos dêiticos da enunciação original. No corpus estudado neste trabalho, formado por sequências narrativas de reportagens, não houve ocorrências dessa forma de discurso representado, o que pode se explicar pela preocupação do jornalista de impedir que o leitor atribua a ele a fala de um terceiro.

Diluindo ainda mais a fronteira entre o discurso produzido e o representado, o discurso indireto implícito não permite uma delimitação clara da voz do locutor e das vozes dos enunciadores. Apenas o contexto possibilita ao leitor precisar qual instância se responsabiliza por um segmento de discurso indireto implícito. Pode ajudar nessa tarefa a presença de elementos dêiticos remetendo à enunciação representada.

No polo direito do contínuo, o discurso indireto explícito corresponde ao grau máximo de absorção do discurso representado pelo produzido. Com essa forma de discurso representado, a enunciação representada perde totalmente sua autonomia em relação à enunciação produzida, já que o que interessa àquele que emprega essa forma de discurso representado é focalizar o conteúdo (o dito) expresso por um terceiro e não a maneira ou o modo (o dizer) como esse conteúdo foi expresso.

Dispondo as formas de discurso representado ao longo de um contínuo, este trabalho, que se insere em uma perspectiva enunciativa dos estudos sobre dialogismo e polifonia, demonstra que o estudo dessas formas de discurso não deve se basear apenas em informações de natureza formal (lexical e sintática). Tendo por base o princípio bakhtiniano de que toda produção discursiva é essencialmente dialógica (BAKHTIN/VOLOCHÍNOV, (1986[1929])), o contínuo proposto revela que a distinção entre discursos dialogais e monologais é menos nítida do que possa parecer e que os fatos de polifonia ganham em ser estudados em termos de diferentes graus de absorção da enunciação representada pela enunciação produzida.

Em relação à maneira como o contínuo auxilia especificamente na compreensão do discurso jornalístico, foi possível verificar que cada forma de discurso representado identificada no corpus (discurso direto explícito, 
EID\&A - Revista Eletrônica de Estudos Integrados em Discurso e Argumentação, llhéus, n. 15, jan./jun.2018.

discurso indireto implícito, discurso indireto explícito ${ }^{6}$ ) permite ao jornalista tentar produzir junto ao leitor determinados efeitos de sentido. $O$ grau de absorção do discurso representado pelo produzido que caracteriza cada uma dessas formas permite ao jornalista:

- tentar produzir efeitos de veracidade e objetividade ou mesmo de distanciamento em relação ao dito (discurso direto explícito),

- tentar criar o efeito de que as informações representadas são evidentes (efeito de evidência), proteger suas fontes e/ou condensar em um único segmento informações de diferentes instâncias enunciativas (discurso indireto implícito) ou

- destacar-se como sendo o responsável pela encenação (oposição, aproximação, hierarquização) de diferentes de pontos de vista (discurso indireto explícito).

Nessa perspectiva, a escolha por uma ou outra dessas formas não é insignificante, porque cada uma desempenha papéis argumentativos importantes na construção do discurso jornalístico.

\footnotetext{
${ }^{6}$ Como exposto, no corpus estudado, não houve ocorrências de discurso direto implícito.
} 
EID\&A - Revista Eletrônica de Estudos Integrados em Discurso e Argumentação, Ilhéus, n. 15, jan./jun.2018.

\section{Referências}

AUTHIER-REVUZ, Jacqueline. Heterogeneidade(s) enunciativa(s). Cadernos de Estudos Linguísticos, v. 19, p. 25-42, 1990.

BAKHTIN, Mikhail (VOLOCHÍNOV). Marxismo e filosofia da linguagem. Trad. Michel Lahud e Yara Frateschi Vieira. São Paulo: Hucitec, 1986 [1929].

BRAIT, Beth (Org.). Bakhtin: dialogismo e construção do sentido. Campinas: Ed.UNICAMP, 1997.

CHARAUDEAU, Patrick. Discurso das mídias. Trad. Angela M. S. Corrêa. São Paulo: Contexto, 2006.

CUNHA, Gustavo Ximenes. A construção da narrativa em reportagens. 2013. $601 \mathrm{f}$. Tese (Doutorado em Linguística). Faculdade de Letras, Universidade Federal de Minas Gerais, Belo Horizonte, 2013.

DOLABELLA, Ana Rosa Vidigal. 0 discurso relatado na imprensa brasileira: jogo de estratégias de apropriação de vozes e de construção de efeitos. 1999. 378f. Dissertação (Mestrado em Linguística) - Faculdade de Letras, Universidade Federal de Minas Gerais, Belo Horizonte, 1999.

DUCROT, Oswald. 0 dizer e o dito. Trad. Eduardo Guimarães. Campinas: Pontes Editores, 1987.

FARACO, Carlos Alberto. Linguagem \& diálogo: as ideias linguísticas do Círculo de Bakhtin. São Paulo: Parábola, 2009.

FIORIN, José Luiz. Introdução ao pensamento de Bakhtin. São Paulo: Ática, 2006.

. As astúcias da enunciação: as categorias de pessoa, espaço e tempo. São Paulo: Ática, 2010.

KERBRAT-ORECCHIONI, Catherine. L'énonciation: de la subjectivité dans le langage. Paris: Armand Colin, 1980.

MAINGUENEAU, Dominique. Novas tendências em Análise do Discurso. Trad. Freda Indursky. Campinas: Pontes, 1993.

- Elementos de linguística para o texto literário. Trad. Maria Augusta de Matos. São Paulo: Martins Fontes, 1996.

. Análise de textos de comunicação. Trad. Maria Cecília Pérez de Souza-e-Silva e Décio Rocha. São Paulo: Cortez, 2008.

MARCUSCHI, Luiz Antônio. A ação dos verbos introdutores de opinião. In:

Fenômenos da linguagem: reflexões semânticas e discursivas. Rio de Janeiro: Lucerna, 2007. p. 146-168. 
EID\&A - Revista Eletrônica de Estudos Integrados em Discurso e Argumentação, Ilhéus, n. 15, jan./jun.2018.

PERRIN, Laurent. Du dialogue rapporté aux reprises diaphoniques. Cahiers de linguistique française, v. 16, p. 211-240, 1995.

. De la structure énonciative et de l'organisation polyphonique d'un échange épistolaire. Cahiers de linguistique française, v. 18, p. 129-156, 1996.

RABATEL, Alain. L'effacement énonciatif dans les discours rapportés et ses effets pragmatiques. Langages, n. 156, p. 03-17, 2004.

. Analyse énonciative du point de vue, narration et analyse de discours. Filologia e linguística portuguesa, n. 9, p. 345-368, 2007.

RAMOS, Rui. Heterogeneidade enunciativa no discurso sobre o ambiente na imprensa portuguesa: funcionamento e efeitos do discurso directo. Linguagem em (Dis)curso. v. 7, n. 1, p. 45-70, 2007.

ROULET, Eddy. L'analyse du dialogue dans une approche modulaire des structures du discours: l'exemple du dialogue Romanesque. In: HUNDSNURSCHER, Franz; WEIGAND, Edda (Ed.) Future perspectives of dialogue analysis. Tubingen: Niemeyer, 1995. p. 01-34.

. La description de l'organisation du discours: du dialogue au texte. Paris: Didier, 1999.

ROULET, Eddy; FILLIETTAZ, Laurent; GROBET, Anne. Un modèle et un instrument d'analyse de l'organisation du discours. Berne: Lang, 2001.

Forma de citação sugerida:

CUNHA, Gustavo Ximenes. Por um contínuo das formas de discurso representado. EID\&A - Revista Eletrônica de Estudos Integrados em Discurso e Argumentação, Ilhéus, n. 15, p. 121-142, jan./jun.2018.

Recebido em: 31/03/2018

Aprovado em: 12/06/2018 